정규논문 (Regular Paper)

방송공학회논문지 제 18 권 제2호, 2013년 3월 (JBE Vol. 18, No. 2, March 2013)

http://dx.doi.org/10.5909/JBE.2013.18.2.237

ISSN 2287-9137 (Online) ISSN 1226-7953 (Print)

$$
\begin{aligned}
& \text { 하이브리드 방송 환경 하에서 HTML5 기반 장면구성 기술 } \\
& \text { 조 민 우 }{ }^{a)} \text {, 박 정 욱 }{ }^{a)} \text {, 김 규 헌 }{ }^{a}{ }^{\ddagger}
\end{aligned}
$$

\title{
Scene Composition Technology Based on HTML5 in Hybrid Broadcasting Environment
}

\author{
Minwoo Jo ${ }^{\text {a) }}$, Jungwook Park ${ }^{\mathrm{a})}$, and Kyuheon $\mathrm{Kim}^{\mathrm{a})^{\ddagger}}$
}

요 약

하이브리드 방송(Hybrid Broadcasting) 환경은 다수의 전송경로를 통한 방송·통신 융합 환경이다. 이러한 하이브리드 방송 환경은 기 존 방송망의 대역폭 제한으로 소수의 미디어만을 전달하던 것과 달리, 타 통신 전송망을 동시에 활용함으로써 다수의 미디어를 전달할 수 있다. 현재, 스마트TV를 필두로 방송망과 IP망을 결합한 하이브리드 방송 환경이 조성되어 다양한 서비스가 나타나고 있으며, 스마 트폰 및 태블릿PC와 같은 타 스마트기기에서 또한 머지않아 하이브리드 방송 환경을 통한 서비스가 나타날 것으로 전망된다. 이렇게 다수의 미디어를 동시에 소비할 수 있는 하이브리드 방송 환경을 효과적으로 활용하는 방법의 하나는 장면구성을 이용하는 것이다. 장 면구성은 미디어가 소비되는 시간과 화면상의 공간을 특정함으로써 다수의 미디어를 복합적으로 소비하는 방법이다. 이에 본 논문에서 는 하이브리드 방송 환경에 적합하고, 스마트기기에 쉽게 적용될 수 있도록 HTML5를 기반으로 한 장면구성 기술을 제안한다. 하지만 HTML5의 스크립트 언어 및 스타일 언어를 활용한 미디어의 공간구성 및 시간구성은 처리의 복잡성을 높이고, 사용 가능한 단말기의 제한을 줄 수 있다. 또한, 하나의 HTML5 문서는 하나의 장면만 표현할 수 있다. 따라서 제안하는 장면구성 기술은 마크업 언어를 통 해 미디어의 공간구성 및 시간구성과 다수 장면을 표현할 수 있도록 HTML5를 확장한다. 더불어 하이브리드 방송환경에 적용을 위한 확장을 포함한다. 이를 위해 HTML5 기술 및 제안하는 장면구성 기술을 소개하고, 구현 및 실험을 통해 본 제안을 검증한다.

\begin{abstract}
Hybrid broadcasting environment is convergence of broadcasting and communication environment. In hybrid broadcasting environment, a number of media can be delivered using both broadcasting channel and other network unlike traditional broadcast environment that is able to deliver a couple of media by the limited bandwidth. Now, starting with smart TV, hybrid broadcasting environment combining broadcasting channel and IP network is established, and a variety of services are appearing. Moreover, the services using hybrid broadcasting environment are expected to appear soon for the other smart terminals such as smart phone and tablet PC. Scene composition is one of the methods that can consume effectively a number of media delivered from hybrid broadcasting environment. Using scene composition, multiple media can be consumed through the specified presentation time and space. Therefore, in this paper, it proposes the scene composition technology that is suitable for hybrid broadcasting environment and smart terminals. However, the spatial composition and temporal composition of media using script language and style language of HTML5 might increase the complexity of processing, and cause limitation of avaliable terminals. Also, a document of HTML5 can describe only one scene. By these reason, the proposed scene composition technology extends HTML5 in order to provide the spatial and temporal composition of media and description of multiple scene through markup language. In addition, it includes the extension of HTML5 in terms of utilization in hybrid broadcasting environment. For this proposal, this paper describes the technology of HTML5 and proposed scene composition. Also, it verifies the scene composition with both implementations and experiments.
\end{abstract}

Keyword : hybrid broadcasting, HTML5, scene composition 


\section{I. 서 론}

광대역의 초고속 통신망이 보급됨에 따라 인터넷을 통한 고화질 비디오 서비스가 가능하게 되었고, 방송 이외의 매 체를 통한 비디오 콘텐츠 소비가 증가하게 되었다. 이에 따 라 IT 사업자들과 가전사들이 방송 플랫폼 사업에 진출하 는 등 전통적인 방송 산업 구조에도 변화가 일어나고 있으 며, IPTV와 인터넷 TV 서비스 등의 방송 및 통신의 융합서 비스가 본격화되고 있다 ${ }^{[1]}$.

하이브리드 방송(Hybrid Broadcasting) 환경은 다수의 전 송경로를 통한 방송·통신 융합 환경으로 IPTV, 위성방송, 케이블TV, 지상파방송, 초고속 인터넷, 인터넷전화(VoIP) 등의 전송 경로 중 둘 이상을 선택적으로 결합한 방송 환경 이다. 하이브리드 방송은 기존의 전송망을 활용하기 때문 에 시스템 구축에 필요한 비용과 시간이 비교적 적으며, 단 일 망에 비해 대용량의 전송이 가능하다는 장점을 가지고 있다. 현재는 스마트TV를 필두로 방송망과 IP망을 결합한 하이브리드 방송 환경이 가장 먼저 조성되어 다양한 서비 스가 나타나고 있으며, 스마트폰 및 태블릿PC와 같은 타 스마트기기에서 또한 머지않아 하이브리드 방송 환경을 통 한 서비스가 나타날 것으로 전망된다. 이러한 실정에 따라 국내의 $\mathrm{OHTV}(\mathrm{Open}$ Hybrid TV)와 국외의 HbbTV(Hybrid Broadcast Broadband TV), ATSC 2.0(Advanced Television Systems Committee)와 같이 하이브리드 방송 환경과 관련 된 표준화가 진행되고 있다 ${ }^{[2]}$. 국제 표준화단체 $\mathrm{MPEG}$ (Moving Picture Expert Group) 또한 새로운 방송전송표준 인 MMT(ISO/IEC 23008-1 MPEG Media Transport)에서 하이브리드 방송 환경을 고려한 표준화를 진행 중이다 ${ }^{[3]}$. 이러한 하이브리드 방송 환경을 효과적으로 활용할 수 있 는 방법의 하나는 장면구성을 이용하는 것이다. 장면구성은

\footnotetext{
a) 경희대학교 전자전파공학과 (Department of Electronics and Radio Engineering, Kyung Hee University)

‡ Corresponding Author : 김규헌(Kyuheon Kim) E-mail: kyuheonkim@khu.ac.kr Tel: +82-31-201-3810

※ 본 연구는 지식경제부 및 정보통신산업진흥원의 대학IT연구센터육성 지원사업의 연구결과로 수행되었음" (NIPA-2012- H0301-12-1006) Manuscript received December 31, 2012 Revised February 26, 2013 Accepted February 26, 2013
}

미디어가 소비되는 시간과 화면상의 공간을 특정함으로써 다수의 미디어를 복합적으로 소비하는 기술이다. 이와 같은 장면구성을 통해 다양한 미디어를 동시에 제공할 수 있음으 로써 하이브리드 방송 환경의 장점을 극대화할 수 있다.

현재 표준화된 장면구성 기술에는 MPEG의 $\mathrm{BIFS(ISO/}$ IEC 14496-11 Scene description and application engine)와 LASeR(ISO/IEC 14496-20 Lightweight Application Scene Representation (LASeR) and Simple Aggregation Format (SAF)), W3C의 SMIL(Synchronized Multimedia Integration Language) 등이 있다. 이와 같은 장면구성 기술들은 각각의 장점이 존재함에도 적용 가능한 환경의 제약과 다양한 기기 에 적용이 어려운 점, 활용의 복잡성 등의 이유로 사용이 미 비한 실정이다. 이러한 기존 장면구성 기술들의 약점을 극복 할 수 있는 기술로 다양한 미디어를 활용할 수 있고, 미디어 의 화면상 공간구성을 제공할 수 있으며, 다수의 가전사에서 각종 스마트 기기에 적용될 것으로 예상되는 HTML5 (Hypertext Markup Language 5)를 고려할 수 있다 ${ }^{[4]}$.

하지만 HTML5는 많은 장점에도 불구하고 하이브리드 방송환경을 위한 장면구성 기술로서 사용되기에 부적절한 면이 있다. 이는 HTML5가 웹문서를 제작하기 위한 마크업 언어이기 때문에 나타나는 것으로 미디어의 시간구성 부재, 스크립트 및 스타일 언어 사용으로 인한 복잡성 등을 들 수 있다.

따라서 본 논문의 II장에서는 HTML5의 미디어의 소비 방법 및 공간구성 방법을 통해 HTML5의 강점 및 약점을 소개하고, 이어서 III장에서 하이브리드 방송 환경에 적합 한 장면구성 기술을 제공하기 위해 필요한 HTML5의 확장 방법을 제시한다. IV장에서는 HTML5의 확장을 통해 제안 한 장면구성 기술의 구현 및 검증 결과를 제시하고, 그에 따른 결론을 $\mathrm{V}$ 장에서 기술한다.

\section{W3C HTML5 소개}

\section{HTML5의 멀티미디어 소비 방법}

HTML(Hypertext Markup Language)은 하이퍼텍스트를 
표현하기 위한 마크업 언어로 정의할 수 있으며, 하이퍼텍 스트란 독자가 하나의 문서에서 타 문서로 즉시 접근할 수 있도록 링크 기능을 제공하는 텍스트이다. HTML은 80년 대에 국제표준으로 채택되어 현재까지 월드 와이드 웹의 핵심 마크업언어로 사용되고 있다. HTML5는 HTML의 다 섯 번째 버전으로 $\mathrm{W} 3 \mathrm{C}$ (World Wide Web Consortium)에 서 표준화가 진행 중이며, 현재 Working Draft가 공표된 상 태이다 ${ }^{[4]}$.

네트워크 환경이 발전하고 웹이 활성화됨에 따라 초기의 HTML이 텍스트와 이미지의 소비만을 제공했던 것과 달리 현재의 HTML5는 비디오, 오디오, 이미지, 그래픽 등과 같 이 다양한 미디어의 소비를 제공하게 되었다. 이러한 미디 어들은 종류에 따라 각각의 요소를 통해 HTML5 문서에 기술된다. 각 미디어에 해당하는 요소는 표 1 과 같다.

표 1. 미디어 종류 별 HTML5 요소

Table 1. HTML5 elements according to type of media

\begin{tabular}{|c|c|}
\hline 종류 & 요소 \\
\hline 텍스트 & $\begin{array}{c}<\mathrm{p}>,<\mathrm{a}>,<\text { em }>,<\text { strong }>,<\text { small }>,<\mathrm{s}>,<\text { cite }> \\
<\mathrm{q}>,<\text { dfn }>,<\text { abbr }>,<\text { time }>,<\text { code }>,<\text { var }> \\
<\text { smap }>,<\text { kbd }>,<\text { sub }>,<\text { sup }>,<\mathrm{i}>,<\mathrm{b}>,<\mathrm{u}> \\
<\text { mark }>,<\text { ruby }>,<\mathrm{rt}>,<\mathrm{rp}>,<\text { bdi }>,<\text { bdo }>,<\text { span }>, \\
<\text { br }>,<\text { wbr }>\end{array}$ \\
\hline 이미지 & $<i m g>$ \\
\hline 비디오 & $<$ video $>$ \\
\hline 오디오 & <audio> \\
\hline 그래픽 & <canvas > \\
\hline 기타 & $<$ object>, <embed> \\
\hline
\end{tabular}

텍스트의 경우, 하나의 요소로 제공하게 되면 스타일과 사용방법에 따라 다수의 속성을 정의해야하기 때문에 소비 되는 방법에 따라 여러 요소를 제공한다. 따로 정의되지 않 은 미디어에 대한 기술은 <object>나 <embed> 요소를 통 해 기술한다. 이를 통해 HTML5가 기술할 수 있는 미디어 의 종류가 제한되지 않음을 알 수 있다.

요소로 표현된 미디어는 요소의 속성을 통해 구체적인
소비 방법을 제공한다. 그림 1 에서 기술한 <video> 요소는 'src' 속성을 통해 재생하고자 하는 비디오 자원의 위치를 URL 주소로 나타내며, 'width' 속성과 'height' 속성은 통 해 웹 페이지 상에 나타날 비디오의 크기를 지정한다. 'control' 속성은 비디오의 재생/일시정지와 같은 재생 관련 버튼의 출력여부를 설정할 수 있다.

HTML5 문서에 기술된 미디어는 HTML5 브라우저를 통해 소비된다. 그림 2는 HTML5 브라우저의 미디어 소비 과정을 도식화한 것이다. 사용자가 제시한 URL 주소는 인 터페이스(Interface)를 통해 웹킷(Web Kit)에 전달되고, 웹 킷은 해당되는 웹페이지를 통신 관리자(Communication Manager)에게 요청한다. 통신 관리자는 웹서버(Web Server)로부터 해당 웹페이지의 HTML5 문서를 요청 및 수신 하여 HTML5 파서(HTML5 Parser)에 전달한다. HTML5 파서는 전달받은 HTML5 문서를 통해 DOM트리를 생성하 며, 웹킷은 생성된 DOM트리를 확인한 후, HTML5 문서가 제공하고자하는 웹 페이지를 표시하기 위해 필요한 미디어 의 데이터를 통신 관리자에 요청한다. 통신 관리자는 미디 어 서버(Media Server)로부터 요청받은 미디어를 요청 및 수신한다. 수신한 미디어는 웹킷의 지시에 따라 재생 엔진 (Presentation Engine)에 의해 표시되는 웹 페이지에서 소비 된다. 즉, 웹킷은 지시만 할 뿐, 실제 분석 및 디코딩은 재생 엔진에서 수행한다. 따라서 웹킷은 미디어의 종류와 관계 없이 자신의 역할을 수행하며, 소비 가능한 미디어의 종류 는 재생 엔진의 역량에 따라 좌우된다.

앞서 소개한 것과 같이 HTML5는 다양한 미디어의 소비 를 지원하고 있으며, 더불어 현재 지원하지 못하는 미디어 에 대해서도 확장 가능하다는 것을 알 수 있다. 이는 다양한 미디어를 제공할 수 있는 하이브리드 방송 환경에서 더 유 용하게 활용될 것이다. 반면에 그림 1 과 같이, 미디어 정보 와 화면 표시를 위한 정보의 혼재는 방송환경에서 적용 시, 미디어의 이용 가능 여부 확인에 오랜 시간을 소비하게 될 것이며, 사용자 경험의 저하를 초래할 수 있다.

<video src="http://www.example.com/video1.avi" width="320" height="240" controls="controls"/>

그림 1. HTML5의 <video> 요소 기술 예

Fig. 1. Example of $\langle$ video $>$ element 


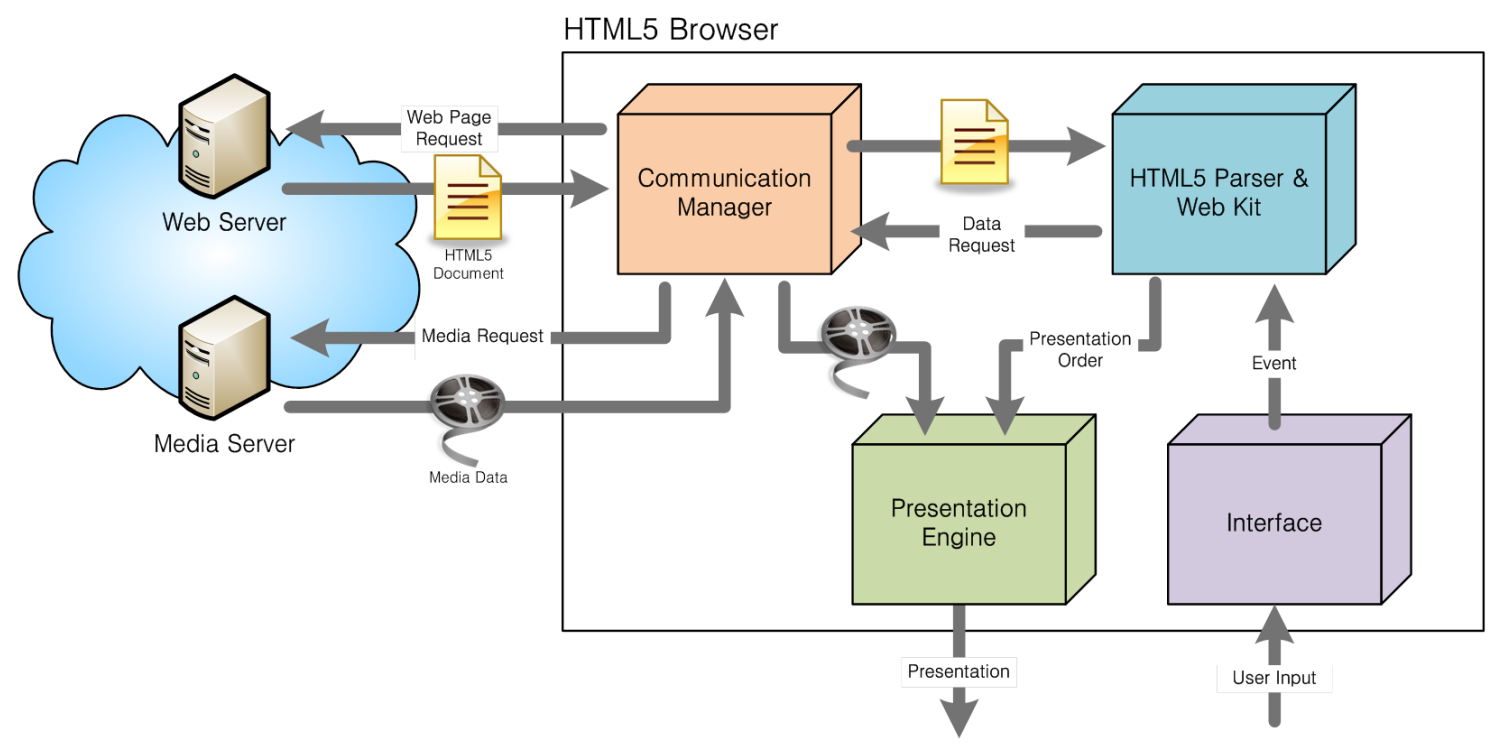

그림 2. HTML5 브라우저의 미디어 소비 과정

Fig. 2. Media consumption process of HTML5 browser

\section{HTML5의 미디어 공간구성 방법}

HTML 5 를 통해 나타나는 미디어는 기본적으로 좌측 상 단을 기준으로 보이며, 미디어의 크기가 실제 단말의 화면 크기보다 클 경우, 스크롤바가 함께 제공된다. 또한 다수의 미디어는 가로로 나열되고, 단말이 이를 모두 보여줄 수 없 는 경우, 세로로 나열하게 된다. 반대로 지정한 미디어의 크기가 실제 단말의 화면 보다 작을 경우, 빈공간은 여백으 로 처리한다. 이와 같은 공간구성 방법은 단말과 사용자의 거리가 가깝고, 입력장치의 활용도가 높은 $\mathrm{PC}$ 환경에서 쉽 게 이용할 수 있지만 TV와 같이 단말과 사용자의 거리가 멀고, 입력장치가 제한된 환경에서는 이용에 많은 불편이 따를 수밖에 없다. 이러한 불편은 HTML5의 레이아웃 요소 를 통해 일정부분 해소할 수 있다.

HTML5의 레이아웃 요소로는 <header>, <nav>, <aside>, $<$ footer>, <article>, <section>, <div>, <iframe> 등이 있다. 각 요소의 공통적인 역할은 웹 페이지 내 특정 영역을 분할 하는 것이며, 사용 용도에 따라 구분된다. 그림 3에서 나타
낸 예와 같이 <header> 요소는 주로 웹 페이지의 상단에 위치하며, 로고 혹은 상호를 나타내는데 주로 사용된다. $<\mathrm{nav}>$ 요소는 메뉴 혹은 내비게이션을 나타내는데 주로 사용되며, 예와 같이 웹 페이지 좌측 혹은 <header>의 하 단에 위치한다. <aside> 요소는 주로 웹 페이지 우측에 위치하며, 사이드바 혹은 보조 미디어를 나타내는데 사 용된다. <footer> 요소는 주로 웹 페이지 하단에서 저작권 정보 및 서비스 제공자 정보를 제공하는데 사용된다. <article> 요소는 중심에 위치하면서 웹 페이지의 주요 내 용을 나타내는데 사용되며, <section> 요소를 포함하거 나, <section> 요소에 포함될 수 있다. <section> 요소도 <article> 요소와 동일한 용도로 사용되나 <article>요소와 달리 내부에 <header> 요소나 <nav> 요소와 같은 타 레이 아웃 요소를 포함할 수 있어, 웹 페이지 상에서 의미적으로 독립적인 형태를 나타내고자 할 때 사용된다. 그림 3에서 나타내지 않은 <div> 요소는 앞서 기술한 의미적 용도 없이 일반적으로 사용할 수 있으며, <iframe> 요소는 분할한 특 정 영역에 타 웹 페이지를 나타내는데 사용된다. 


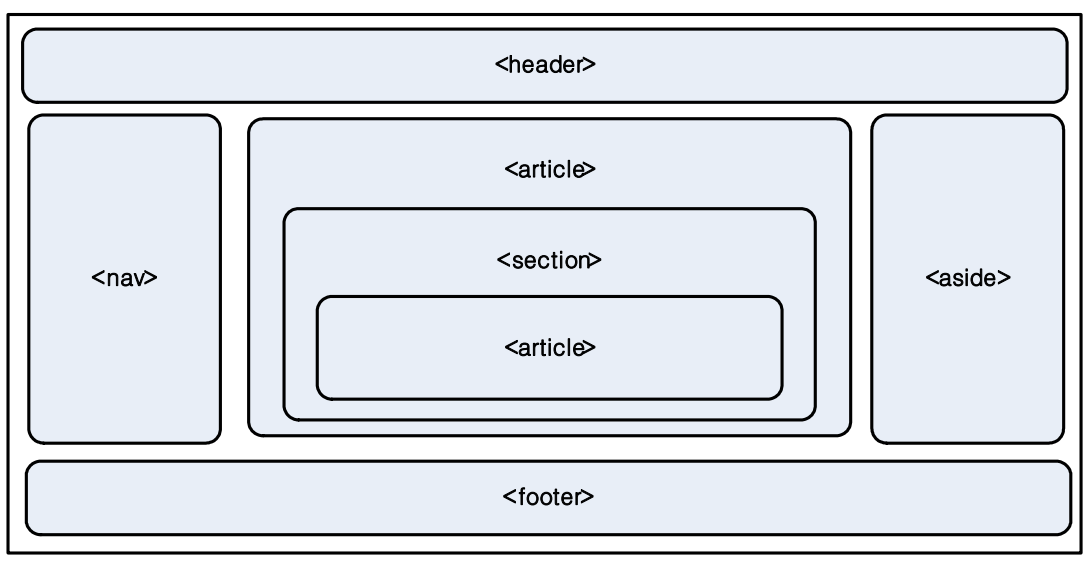

그림 3. HTML5의 레이아웃 요소 사용 예

Fig. 3. Example of using layout element of HTML5

하지만 이러한 HTML5의 레이아웃 요소를 활용할지라 도 앞서 지적한 TV환경에서의 불편 사항은 여전하다. 그 이유는 이들 레이아웃 요소의 속성에서 찾을 수 있는데, 모 든 레이아웃 요소가 화면상에 표시될 특정 좌표에 관한 속 성을 가지고 있지 않으며, 일부는 너비 및 높이와 같은 크기 에 대한 속성마저도 가지고 있지 않기 때문이다. 이러한 부 분을 해결할 수 있는 방법은 HTML5가 지원하는 스타일 언어인 CSS(Cascading Style Sheet)에서 찾을 수 있다.

$\mathrm{CSS}$ 는 마크업 언어가 화면에 실제로 표시되는 방법을 기술하는 언어로, 작성자가 마크업에 레이아웃과 스타일을 정의할 때 유용하게 사용된다. 마크업으로 작성한 미디어 를 $\mathrm{CSS}$ 를 통해 특정 좌표와 크기로 화면상에 표시할 수 있 다. $\mathrm{CSS}$ 는 그림 4과 같은 형태로 기술된다.

선택자 선언 선언

\section{h1 \{color:red; font-size:12px\} 특성 $\uparrow_{\text {닶 }} \uparrow_{\text {성 }}$}

그림 4. CSS 기술 방법

Fig. 4. CSS syntax

선택자는 스타일 정의의 대상이 되는 요소를 기술한다. 각 선언은 스타일을 정의하며, 특성에 해당하는 속성을 값 으로 정의한다. CSS의 특성 중 공간구성과 관련된 중요 특
성과 그 기능은 표 2 와 같다.

표 2. CSS의 공간구성 관련 특성 및 기능

Table 2. Properties and functions in terms of spatial composition in CSS

\begin{tabular}{|c|c|}
\hline 특성 & 설명 \\
\hline position & 요소의 위치 지정 방법을 정의 \\
\hline width & 요소가 표시되는 영역의 너비를 정의 \\
\hline height & 요소가 표시되는 영역의 높이를 정의 \\
\hline top & 요소가 표시되는 영역의 상단 여백 크기를 정의 \\
\hline bottom & 요소가 표시되는 영역의 하단 여백 크기를 정의 \\
\hline left & 요소가 표시되는 영역의 좌측 여백 크기를 정의 \\
\hline right & 요소가 표시되는 영역의 우측 여백 크기를 정의 \\
\hline z-index & 요소가 표시되는 영역이 다른 요소의 영역과 겹칠 경우, \\
표시 순서를 정의
\end{tabular}

방송환경에 적합하도록 미디어의 위치를 정의하거나 영 역을 정의하기 위한 기능을 $\mathrm{CSS}$ 에서 제공하고 있으며, 이 를 통해 기존의 장면구성 기술들과 같은 공간구성 효과를 HTML5로 나타낼 수 있다. 하지만 CSS와 같은 스타일 언 어의 사용은 복잡성을 증가시키고 다양한 단말에 대한 보 편성을 저하시키는 원인이 될 수 있다. 또한 하나의 HTML5 문서가 하나의 장면 밖에 기술할 수 없기 때문에 이에 대한 확장이 필요하다. 


\section{III. 장면구성 제공을 위한 HTML5 확장 방안}

III장에서는 II장에서 소개한 HTML5를 토대로 하이브 리드 방송 환경에 적합한 장면구성 기술을 정의하고자 한 다. 이때 HTML5의 확장 방향은 크게 세 가지로, 미디어의 이용가능 여부를 빠르게 확인할 수 있도록 하여 HTML5를 방송 환경에서 적용하기 위한 확장, 스타일 언어의 사용을 줄이고 다수의 장면을 하나의 HTML5 문서에 기술할 수 있도록 미디어의 공간구성 정보를 제공하기 위한 확장, HTML5가 제공하지 못하는 미디어의 시간구성 정보를 제 공하기 위한 확장이 있으며, 이러한 확장을 통해 제안하는 장면구성 기술의 구조는 그림 5 와 같다.

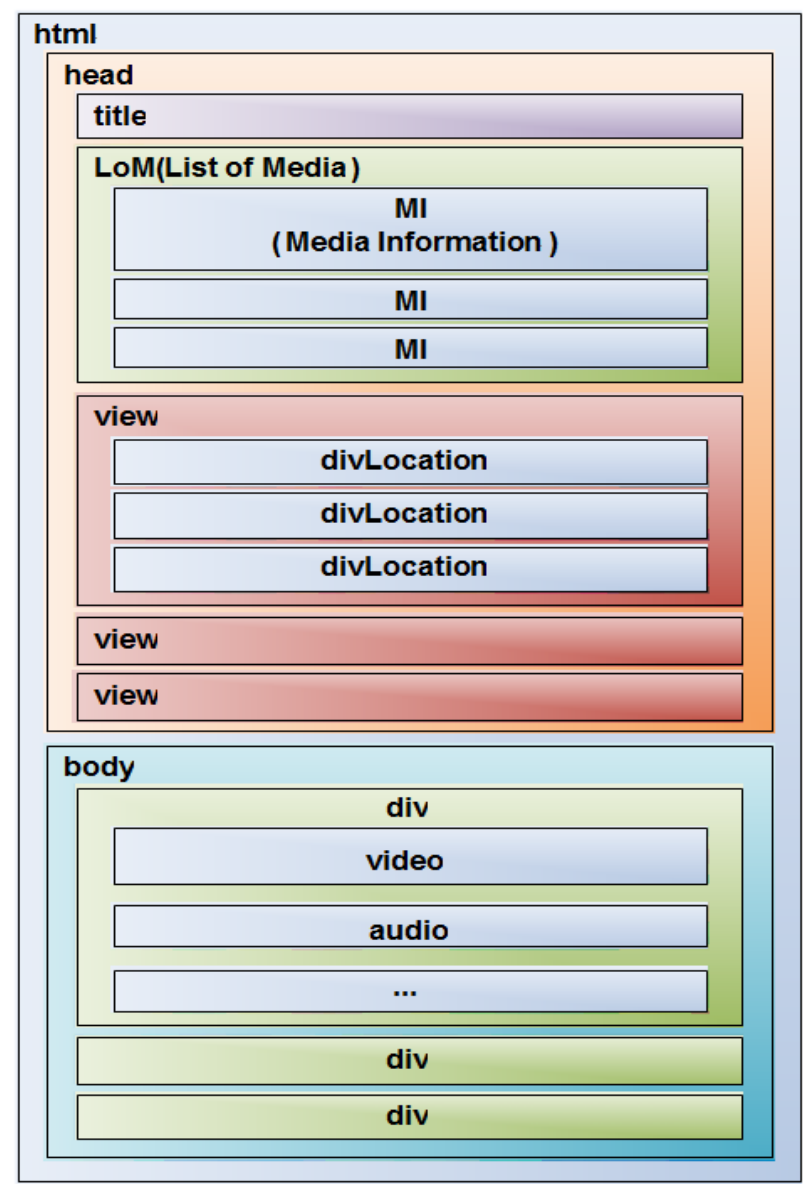

그림 5. 장면구성 기술의 기본 구조

Fig. 5. Basic structure of compositon technology
HTML5 표준에 의하면 HTML5 자체에 대한 요소 및 속 성의 확장은 불가능하기 때문에 본 논문에서는 확장을 허 용하고 있는 XHTML5를 통해 요소 및 속성을 확장한다. 또한 추가된 각 요소들은 HTMLElement를 상속하여, id, title, style 등의 속성을 사용 가능하도록 한다. 이후의 절에 서는 앞서 언급한 세 가지 확장 방향에 따라 구체적인 확장 을 제시한다.

\section{1. 방송환경에 적용을 위한 확장}

방송환경에서 제공하고자 하는 프로그램과 장면구성 정 보의 매칭 여부를 확인하기 위해서 장면구성 정보는 프로 그램의 식별에 필요한 정보를 제공해야 한다. 프로그램 식 별 정보는 프로그램의 제목 혹은 코드 번호 등이 될 수 있을 것이다. 본 논문에서는 프로그램의 제목을 통해 식별하는 경우를 고려하여 HTML5의 <title> 요소를 활용하고자 한 다. 따라서 <title> 요소의 역할을 해당 장면구성 정보의 식 별 및 방송 프로그램의 제목을 제공하는 것으로 확장하여 정의한다.

인터넷 환경과 달리 방송환경은 유료 서비스가 주를 이 루기 때문에 서비스의 품질이 보장되어야 한다. 따라서 서 비스 제공 초기에 미디어들의 이용가능여부에 대한 확인이 필요하다. 기존의 HTML5의 미디어 표현은 그림 1과 같이 미디어 정보가 화면 표시를 위한 정보와 혼재되어 있기 때 문에 방송환경에서 적용 시, 장면구성 정보 전체의 해석을 다 마치고 나서야 이용가능여부를 확인할 수 있다. 따라서 방송 초기화 정보를 쉽게 제공하기 위해 본 논문에서 제안 하는 장면구성 기술은 미디어의 장면구성 관련 정보와 미 디어 정보를 분리하여 제공한다. 분리된 미디어 정보는 그 림 5 에서와 같이 $<\mathrm{head}>$ 요소의 하위 요소인 $<\mathrm{LoM}>$ 요소 와 그 하위 요소인 $<\mathrm{MI}>$ 요소를 통해 기술되며, 서비스에 사용되는 각각의 미디어에 하나의 $<\mathrm{MI}>$ 요소가 할당된다. 미디어 정보는 $<\mathrm{MI}>$ 요소의 속성을 통해 기술되며, 해당 속성과 역할은 표 3 과 같다.

$<\mathrm{MI}>$ 요소를 통해 기술된 미디어의 정보의 중복 기술을 피하기 위해 미디어 요소는 미디어의 정보 대신, $<\mathrm{MI}>$ 요 소와의 참조 정보만을 기술한다. 
표 3. <Ml> 요소의 속성

Table 3. Attributes of $\langle\mathrm{Ml}>$ element

\begin{tabular}{|c|c|}
\hline 속성 & 설명 \\
\hline src & 미디어의 자원 위치를 URI로 기술 \\
\hline mediatype & 미디어의 종류를 기술 \\
\hline profile & $\begin{array}{c}\text { 비디오 및 오디오의 압축방식에 따른 프로파일을 } \\
\text { 코드번호 혹은 URN으로 기술 } \\
\text { (mediatype이 비디오 혹은 오디오일 경우에만 유효) }\end{array}$ \\
\hline level & $\begin{array}{c}\text { 비디오 및 오디오의 압축방식에 따른 레벨을 양의 } \\
\text { 정수로 기술 } \\
\text { (mediatype이 비디오 혹은 오디오일 경우에만 유효) }\end{array}$ \\
\hline
\end{tabular}

\section{2. 공간구성 정보를 위한 확장}

HTML5가 제공하는 공간구성을 활용하면서 하나의 HTML5 문서에 다수의 장면을 기술할 수 있도록 본 논문에 서는 그림 6 와 같은 장면구성 개념을 도입한다. 하나의 장 면은 View의 개념으로 대치되며, View는 Area의 조합으로 이루어진다. Area는 장면의 일부를 독립적으로 구성한다. 미디어는 Area 내에서 구성된다. 이러한 구조는 반복적으 로 나타나는 미디어에 대한 중복 기술을 줄이고, 장면의 일 부를 독립적으로 변경하는데 용이하다.

Area를 장면구성 정보 내 요소로 표현하기 위해 HTML5 의 <div> 요소를 확장한다. < div> 요소는 앞서 II장에서 기 술한 바와 같이, 웹 페이지 내 특정 영역을 분할하는 역할을 하며, 특정한 의미적 용도 없이 일반적으로 사용할 수 있기 때문에 Area와 역할이 유사하고, 의미적 용도에 대한 충돌
도 타 요소에 비해 적다.

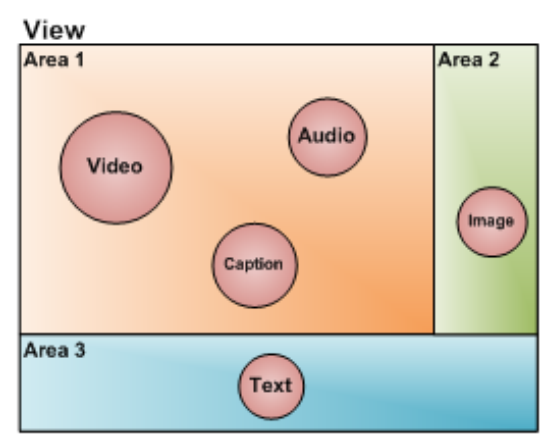

그림 6. 장면구성 개념도

Fig. 6. Concept of scene composition

View는 대치되는 개념의 HTML5 요소가 존재하지 않으 므로 <view> 요소를 새로이 추가하며, 실제로 보이는 미디 어의 정보를 담고 있지 않기 때문에 <head> 요소의 하위 요소로 정의한다. 또한, 해당 View를 구성하는 각 Area의 조합 정보를 제공하기 위해, <view> 요소의 하위 요소로 $<$ divLocation> 요소를 정의하며, 각 <divLocation> 요소는 해당 Area의 조합정보와 참조정보를 포함한다.

그림 7은 View와 Area와 미디어 간의 공간구성 관계에 따른 화면 표시 과정을 도식화 한 것이다. 하이브리드 방송 환경을 통해 전달 된 미디어는 공간구성 정보에 의해 Area 로 구성되며, Area 또한 공간구성 정보에 의해 View로 구 성된다.

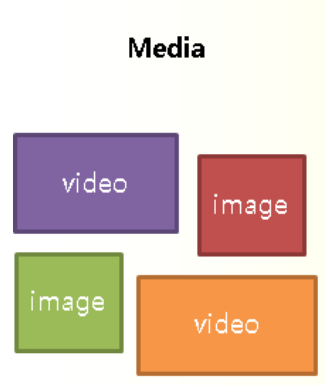

Area 1

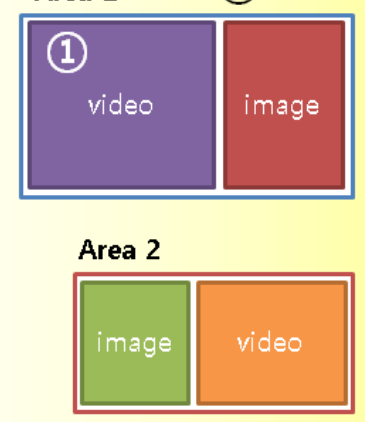

view

(4)

(3)

Area 1

Area 2

그림 7. View와 Area와 미디어 간의 공간구성 관계에 따른 화면 표시 과정

Fig. 7. Screen display process according to spatial composition relationship among View, Area, and media 
이와 같은 화면 표시 과정에서 총 네 가지의 공간구성 정보가 필요하다. 첫 번째는 그림 7의 (1)에 해당하는 미디 어를 Area 내에서 특정 영역에 배치하기 위한 위치 정보와 크기 정보, 두 번째는 (2)에 해당하는 Area의 크기 정보, 세 번째는 (3)에 해당하는 Area를 View 내에서 특정 영역에 배치하기 위한 위치정보와 크기 정보, 네 번째는 (4)에 해당 하는 View의 크기 정보이다. 또한, 각각의 공간구성 정보와 요소 간의 관계를 살펴보면 (1)은 미디어 요소에, (2)는 $<\operatorname{div}>$ 요소에, (3)은 <divLocation> 요소에, (4)는 <view> 요 소에 해당하는 공간구성 정보이다.

표 4는 앞서 언급한 네 가지 공간구성 정보에 따라 각 요소의 속성을 정의한 것이다.

표 4와 같이 정의한 공간구성 정보에 의해 View에서 표 시되는 미디어의 크기는 다음과 같은 수식으로 계산할 수 있다.

위의 수식에서 < divLocation> 요소의 너비/높이를 < div> 요소의 너비/높이로 나눈 값은 미디어 요소의 너비/높이를 View 내의 미디어 영역의 너비/높이에 대한 비율 값이 된
다. 이 수식을 통해 미디어를 화면에 표시하기 위한 확대 및 축소는 Area 내의 미디어 영역의 크기 조정을 생략하고 직접 View 내의 미디어 영역의 크기로 적용할 수 있다.

\section{3. 시간구성 정보를 위한 확장}

장면구성에서 시간구성 정보는 다수의 미디어를 의미적 으로 나열하기 위해 사용된다. HTML5를 통한 미디어의 시 간구성 방법은 존재하지 않으며, 스크립트를 통해 유사한 기능을 제공하는 것은 가능하다. 하지만 이러한 스크립트 의 사용은 단말에 부담을 주며, 장면구성 정보 분석에 지연 시간을 증가시킨다. 따라서 본 논문에서는 시간 구성 정보 를 요소의 속성으로 정의하며, 추가되는 속성은 'begin', 'end', 'dur'이다.

이 세 가지 속성은 2절에서 소개한 장면구성 개념에 따라 미디어 요소, <divLocation> 요소, <view> 요소의 속성으 로 정의한다. 'begin' 속성은 해당 요소의 활성 시작 시간을 정의한다. 'end' 속성은 해당 요소의 활성 종료 시간을 정의

$$
\begin{aligned}
& (\text { View } \text { 내의 미디어 영역 너비 })=(\text { 미디어 요소의 width }) \times \frac{(<\text { divLocation }>\text { 요소의 width })}{(<\operatorname{div}>\text { 요소의 width })} \\
& (\text { View 내의 미디어 영역 높이 })=(\text { 미디어 요소의 height }) \times \frac{(<\text { divLocation }>\text { 요소의 height })}{(<\text { div }>\text { 요소의 height })}
\end{aligned}
$$

표 4. 공간구성 정보 제공을 위한 요소 별 속성

\begin{tabular}{|c|c|c|}
\hline 요소 & 공간구성 관련 속성 & 정의 \\
\hline \multirow{4}{*}{ 미디어 요소 (<video>, <img>, ...) } & top & 미디어가 Area 내에서 표시되는 영역의 상단 여백 크기를 정의 \\
\hline & left & 미디어가 Area 내에서 표시되는 영역의 좌측 여백 크기를 정의 \\
\hline & width & 미디어가 Area 내에서 표시되는 영역의 너비를 정의 \\
\hline & height & 미디어가 Area 내에서 표시되는 영역의 높이를 정의 \\
\hline \multirow{2}{*}{$<$ div $>$} & width & Area의 너비를 정의 \\
\hline & height & Area의 높이를 정의 \\
\hline \multirow{4}{*}{ <divLocation> } & top & Area가 View 내에서 표시되는 영역의 상단 여백 크기를 정의 \\
\hline & left & Area가 View 내에서 표시되는 영역의 좌측 여백 크기를 정의 \\
\hline & width & Area가 View 내에서 표시되는 영역의 너비를 정의 \\
\hline & height & Area가 View 내에서 표시되는 영역의 높이를 정의 \\
\hline \multirow{2}{*}{$<$ view $>$} & width & View의 너비를 정의 \\
\hline & height & View의 높이를 정의 \\
\hline
\end{tabular}

Table 4. Attributes of each elements for providing spatial composition information 
표 5. begin/end 속성의 값 및 사용 예

Table 5. Values and examples of begin/end attribute

\begin{tabular}{|c|c|c|}
\hline 값의 종류 & 값의 정의 & 값의 사용 예 \\
\hline 상대시간 & $\begin{array}{c}<\text { view> 요소의 경우, 장면구성 시작을 기준으로 한 상대시간. <divLocation> 요소의 } \\
\text { 경우, 상위 <view> 요소의 활성 시작을 기준으로 한 상대시간. 미디어 요소의 경우, } \\
\text { 상위 <div> 요소를 참조하는 <divLocation> 요소의 활성 시작 시간을 기준으로 한 } \\
\text { 상대시간. 시, 분, 초, } 1 / 100 \text { 초 단위로 기술. }\end{array}$ & $\begin{array}{l}\text { begin=“10s" } \\
\text { end=“30min" }\end{array}$ \\
\hline 동기시점 & 타 요소의 활성 시작, 혹은 종류 시점. 타 요소의 id와 begin(시작), end(종료)로 기술. & $\begin{array}{l}\text { begin="area1.begin" } \\
\text { begin="area1.end" }\end{array}$ \\
\hline 이벤트시점 & 이벤트 발생 시점. 이벤트 대상 요소의 id와 이벤트 이름으로 기술 & begin="video1.click" \\
\hline 절대시간 & 현실 시간을 기준으로 한 절대시간. & begin=“18:00" \\
\hline
\end{tabular}

한다. 'dur' 속성은 해당 요소의 활성 시작으로부터 활성 기 간을 정의한다. 따라서 요소의 시간구성 정보를 제공하기 위해 'begin'과 'end' 속성 혹은 'begin'과 'dur' 속성이 필 요하다. 'begin'과 'end' 속성의 값은 상대시간, 동기시점, 이벤트, 절대시간의 네 가지가 있으며, 각각의 정의 및 사용 예는 표 5 와 같다. 'dur' 속성의 값은 시, 분, 초, $1 / 100$ 초 단위로 기술한다.

\section{HTML5 기반 장면구성 기술 구현 및 검증}

\section{HTML5 기반 장면구성 시스템}

본 논문에서는 하이브리드 방송 환경을 고려한 HTML 5 기반 장면구성 기술을 제안하였다. 제안한 내용을 검증하 기 위해 $\mathrm{PC}$ 환경에서 그림 8 과 같이 장면구성 시스템을 구 현하고 실험하였다.
장면구성 정보를 담고 있는 장면구성 문서와 관련된 비 디오 파일을 서버에 저장하였다. 클라이언트는 장면구성 문서를 요청하고 전달받아 장면구성 파서(Scene Composition Parser)로 분석하여 장면구성 정보를 장면구성 모듈 (Scene Composition Module)로 전달한다. 장면구성 모듈은 전달받은 장면구성 정보의 시간구성에 따라 필요한 비디오 파일을 서버에 요청하여 전달받고, 비디오 파서(Video Parser) 및 비디오 디코더(Video Decoder)를 거쳐 렌더러 (Renderer)에 전달된 비디오를 장면구성 정보의 공간구성 에 따라 알맞은 영역에 표시되도록 한다.

HTML5 기반 장면구성 시스템에서 실험을 목적으로 미 디어는 비디오만, 시간구성 정보는 상대시간의 초 단위만 사용가능하도록 하였다. 구현은 다음과 같은 개발환경에서 이루어졌다. 운영체제는 Windows 7 (64bits)을 사용하였고, 컴파일러 및 언어는 Microsoft visual studio $2008 \mathrm{C} / \mathrm{C}+1$ 를 사용하였으며, Renderer에는 DirectX February 2010의 direct draw를 사용하였다.

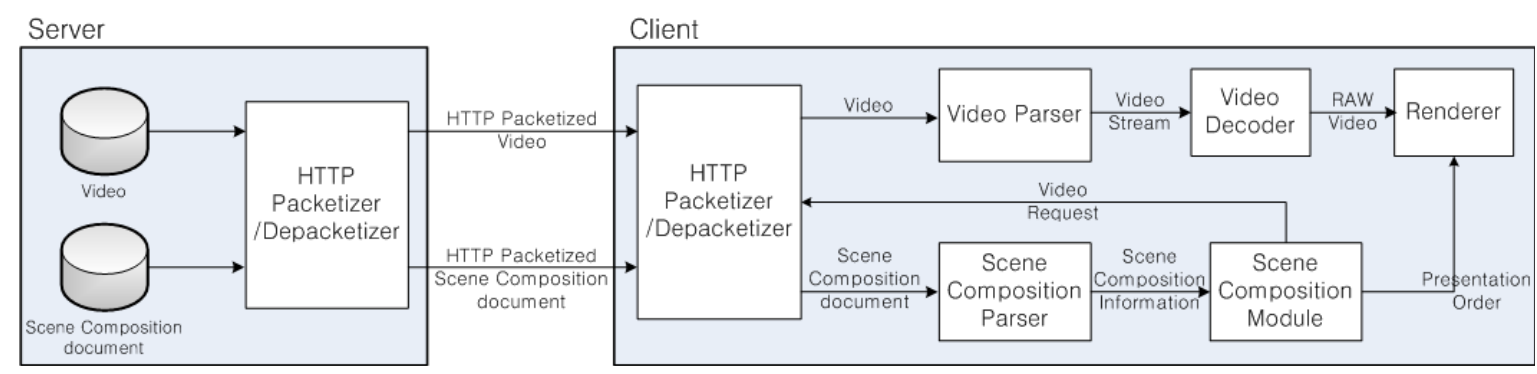

그림 8. 장면구성 시스템

Fig. 8. Scene composition system 


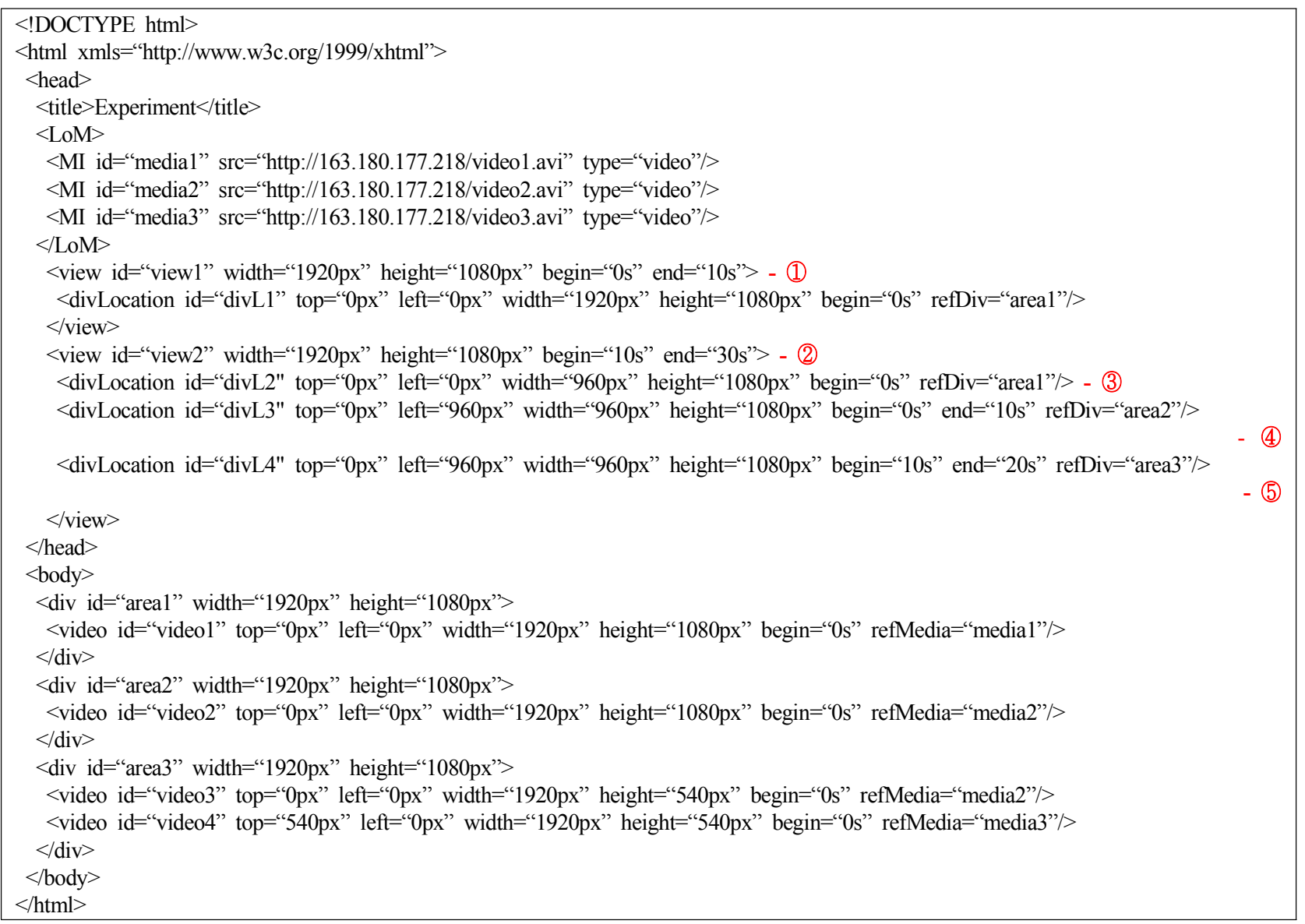

그림 9. 실험에 사용된 장면구성 문서

Fig. 9. Scene composition document for experiment

\section{2. 실험 및 검증}

실험을 위해 그림 9 의 장면구성 정보를 사용하였다. 기 술된 내용에 따라 4 개의 미디어가 지정된 공간과 시간에 재생된다. 재생시작부터 10초간 (1)의 "view1"에 의해 "divL1"이 활성화되어

"areal"의 "medial"이 전체화면에 재생된다. 10초 이후 에는 (2)의 "view2"로 장면이 전환되며, 10 초부터 20 초 사 이에 (3)의 "divL2"에 의해 화면 좌측에 "areal"의 "medial" 이, (4)의 "divL3"에 의해 화면 우측에 "area2"의 "media2" 가 재생된다. 20 초부터 30 초 사이에는 (3)의 "divL2"에 의해 화면 좌측에 "medial"이 계속 재생되며, (5)의 "divL4"에 의
해 "area3"이 활성화되어 우측 상단에 "media2", 우측 하단 에 "media3"가 재생된다.

그림 10은 HTML5 기반 장면구성 시스템이 본 논문 에서 제안한 장면구성 방법에 따라 그림 9의 장면구성 문서를 통해 미디어를 재생하는 장면을 보여준다. 그림 10 의 (a)에서 "view1"에 따라 "areal"의 "medial"을 재 생하는 것을 확인할 수 있었고, 그림 10 의 (b)에서 "view2"에 의해 "area1"의 "media1"과 "area2"의 "media2"가 공간구성에 따라 재생하는 것을 확인할 수 있었으며, 그림 10의 (c)에서 "area2"가 종료되고 "area3"에 의해 "media2"와 "media3"가 추가로 재생되 는 것을 확인할 수 있었다. 


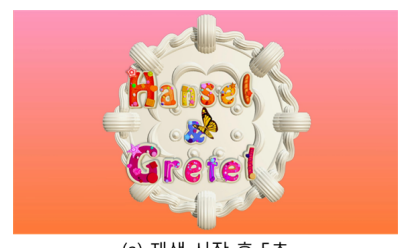

(a) 재생 시작 후 5 초

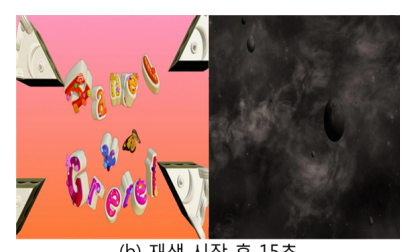

(b) 재생 시작 후 15 초

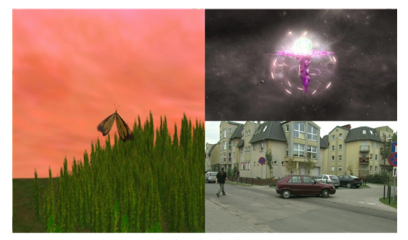

(c) 재생 시작 후 25 초

그림 10. 장면구성 문서 재생 화면

Fig. 10. Playback of the scene composition document

\section{V. 결 론}

장면구성은 다수의 미디어를 동시에 소비하는데 있어 미 디어의 공간구성과 시간구성을 제공함으로써 하이브리드 방송 환경과 같이 다수의 미디어를 전송할 수 있는 환경에 서 유용하게 사용될 수 있다. 본 논문에서는 하이브리드 방
송 환경에 적합한 HTML5 기반 장면구성 기술을 제안하고 구현 및 검증하였다. 이를 통해 실제 방송에 대한 장면구성 의 적용과 HTML5를 지원하는 다양한 스마트기기에 대한 활용이 가능하고, 더불어 멀티뷰 서비스나 증강방송 서비 스, 광고 비즈니스 등과 같이 다양한 부가 서비스 및 수익 모델의 창출에 기여할 수 있을 것으로 기대된다. 또한, 장면 구성 기술을 필요로 하는 다른 멀티미디어 서비스 기술 개 방의 방향성을 제시할 수 있을 것이다.

\section{참 고 문 헌}

[1] Hoyoung Kwon, Youngsoo Kim, "Changes in the pay TV market due to the advent of IPTV" Korean Broadcasting Institute, September 2008

[2] Jinpil Kim, "Standardization Trend of Hybrid Broadcast and Broadband TV" TTA Journal, March 2010

[3] MPEG, "Proposal for MMT-CI architecture based on HTML5", ISO/IEC JTC1/SC29/WG11/M26162, July 2012

[4] W3C, "HyperText Markup Language (HTML5) Working Draft 29“, March 2012 (http://www.w3.org/TR/htm15/)

[5] Minwoo Jo, Jungwook Park, Kyuheon Kim, "The method of scene composition based on hybrid broadcasting environment", Korea Society of Broadcast Engineers Fall Conference, November 2012

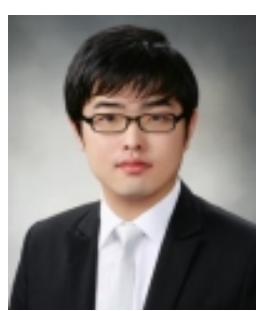

\section{조 민 우}

- 2011년 2월 : 경희대학교 전자공학 학사

- 2011년 9월 현재 : 경희대학교 전자전파공학 석사

- 주관심분야 : 멀티미디어 시스템, MPEG 장면 구성 기술 
저 자 소 개

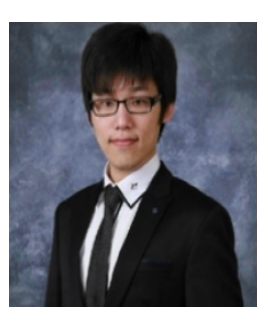

박 정 욱

- 2010년 9월 : 경희대학교 전자전파공학 학사

- 2013년 2월 : 경희대학교 전자전파공학 석사

- 주관심분야 : 멀티미디어, MPEG- DASH, MPEG-LASeR

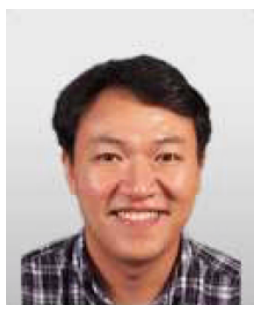

김 규 헌

- 1989년 2월 : 한양대학교 전자공학과 공학사

- 1992년 9월 : 영국 University of Newcastle upon Tyne 전기전자공학과 공학석사

- 1996년 7월 : 영국 University of Newcastle upon Tyne 전기전자공학과 공학박사

- 1996년 1997년 : 영국 University of Sheffield, Research Fellow

- 1997년 2006년 : 한국전자통신연구원 대화형미디어연구팀장

- 2006년 현재 : 경희대학교 전자정보대학 교수

- 주관심분야 : 영상처리, 멀티미디어통신, 디지털 대화형방송 